\title{
KUZEY MAKEDONYA-VALANDOVA-ÇALIKLI KÖYÜNDE TÜRKAN ZULFIKAROVA'NIN DOKUDUĞU ÇARŞAFLIK KUMAŞLAR
}

\author{
BED SHEET FABRICS WOVEN BY TÜRKAN ZULFIKAROVA IN ÇALIKLI VILLAGE- \\ VALANDOVO- NORTH MACEDONIA
}

\author{
Ülkü Küçükkurt ${ }^{*}$
}

\section{Öz}

Türkler, Kuzey Makedonya'nın bazı bölgelerinde uzun yıllardan beri yaşamaktadırlar. Çalıklı, Kuzey Makedonya'nın güney doğusunda bulunan Valandova'ya bağlı Türklerin yaşadığı bir köydür. Köyün insanları Türk gelenek ve göreneklerini, inançlarını, el sanatlarını günümüzde uygulamaya hala devam etmektedir. Çalıkıının el sanatları arasında önemli bir yere sahip olan çarşafık kumaş dokumalarının günümüzde üretimi azalmış, dokumayı bilen kişi sayısında azalm meydana gelmiştir. Dokuma tezgâhını kurarak geleneksel yöntemle kumaş dokuyan ustalardan biri Türkan Zulfikarova'dır. Araştırmanın amacını, geleneksel çarşaflık kumaş dokuma sanatını Çalıklı köyünde yaşatan Türkan Zulfikarova'nın dokuduğu örnekler ışığında yörenin çarşaflık dokuma kumaş özelliklerinin, üretimde kullanılan hammaddelerin, araç ve gereçlerin, uygulanan tekniklerin, dokumaya ait terimlerin tespit edilmesi oluşturmaktadır. Araştırmanın yönteminde alan araştırması ve literatür taraması kullanıımıştır. Araştırmada, geleneksel çarşaf dokumalarında kullanılan ipliklerin tedarik güçlüğü, gençlerin bu konuya yeterli ilgi göstermemesi gibi nedenlerle dokumacılığın kaybolma tehlikesi ile karşı karşıya kaldığı sonucunda varılmıştır. Makalede, yörede kumaş dokumacılığının yaşatılması için önerilerde bulunulmuştur.

Anahtar Kelimeler: Kuzey Makedonya, Çalıklı, Kumaş Dokuma, Çarşaflık Kumaş, El Sanatı.

\begin{abstract}
Turks have lived in certain regions of North Macedonia for many years. Çalıklı is a village of Valandovo, located in the southeast of North Macedonia and populated by the Turks. The residents of the village continue to practice Turkish traditions and customs, beliefs and handicrafts. Today, the production of sheeting fabric weaves, which is among the most important handicrafts in Çalıklı, has decreased along with the number of people who know how to weave them. Türkan Zulfikarova is among the weaving artists who weave fabric using traditional methods. The present study aims to determine the fabric properties, raw materials, tools, techniques, and terms used in relation to the sheeting weave handicraft of the region in light of the examples produced by Türkan Zulfikarova, who keeps the art of traditional sheet weaving alive in the Çalıklı village. Field research and literature review were used in the method of the study. In the study, it was concluded that weaving faced the danger of disappearing due to the difficulty in procuring the yarns used in traditional sheet weaving and the young people not showing enough interest in this subject. In the article, suggestions are made for the survival of fabric weaving in the region.
\end{abstract}

Keywords: North Macedonia, Çalıklı, Fabric Weaving, Bed Sheet Fabric, Handicraft.

\footnotetext{
Araştırma Makalesi // Başvuru tarihi: 14.09.2020 - Kabul tarihi: 12.12.2020.

* Dr. Öğretim Üyesi, Afyon Kocatepe Üniversitesi, Güzel Sanatlar Fakültesi, Geleneksel Türk Sanatları Bölümü, Afyonkarahisar, ukkurt@aku.edu.tr, https://orcid.org/0000-0001-8140-5357.
} 


\section{Giriş}

Balkan ülkelerinden biri olan Kuzey Makedonya'nın bazı bölgelerinde Türkler uzun yıllardan beri yaşamakta, kültürlerini, el sanatlarını korumaktadır. Türklerin Kuzey Makedonya'ya göç etmesi Osmanlı döneminden önce başladığı, en yoğun göçün Anadolu Yörüklerinin öncülüğünde I. Beyazıt döneminde olduğu çeşitli kaynaklarda belirtilmektedir. Yörükler, Anadolu'nun orta ve batı kısmı ile Marmara Bölgesi'nden Balkanlar’a göç yolculuğuna başlamış, Balkanlar'a ulaştıklarında bölgelere dağılarak yerleşmiştir. Göç eden topluluğun bir bölümü Kuzey Makedonya'nın doğusuna yönelerek dağ yamaçlarında yerleşik hayata geçmiştir. Göçlerin amacı bölgenin "Şenlendirilmesi"dir. Bu tabir; insansız yerlerin, yol ve sınır güvenliğinin sağlanması, yerleşime açılarak tehlikenin uzaklaştırılması için kullanılmıştır. Anadolu'dan Balkanlara insan göçü XV ve XVI. yüzyıllarda hızla devam ederken XVII. yüzyılda sona ermiştir (Adiller, 2013:182). Osmanlı-Türk egemenliği Balkanlarda yaklaşık beş yüzyıl sürmüş, barış ve huzur içinde yaşanmış, Türk halkı bu coğrafyanın kültürünü etkilemiştir. 2016 yılında yapılan bir araştırmada resmi rakamlara göre 78 bin, gayrı resmî rakamlara göre ise yaklaşık 100 ile 150 bin arasında Türk Kuzey Makedonya'da yaşamaktadır (Nureski, 2016:385). Bugün bahsedilen bölgelerde varlıklarını sürdürmeye çalışan ve sayıları her geçen gün azalan Türklerin büyük bir kısmı bazı siyasi, ekonomik, sosyal sebeplerden dolayı geldikleri ata topraklarına göçü istemektedir. Göç edenlerin sayısı her geçen gün artmaktadır (Adiller, 2013:182).

Şenlendirmeyle oluşan köylerden birisi Çalıklı köyüdür. Çalıklı, Kuzey Makedonya'nın güney doğusunda Valandova'ya bağlı Türklerin yaşadığı bir köydür. Üsküp'e 157 km, Valandova'ya 6,82 km uzaklıkta, geçimini tarım ve hayvancılıktan sağlamaktadır. Tarım faaliyeti içinde tütün ekimi önde gelmektedir. Kuzey Makedonya-Valandova bölgesinde Türk köyü olarak Çalıkıının yanı sıra Bahçebosu köyü, Bayrambosu köyü, Dedeli köyü, Çeştova köyü, Çepelli köyü, Kayalı köyü, İzleş köyü, Cumabosu köyü, Çavuşlu köyü, Memişli köyü, Kurdhamzalı köyü, Durutlu köyü, Urgancılı köyü, Ormanlı köyü, Buluntulu köyü, Pıristan köyü, Koçullu köyü, Durulobosu köyü gibi daha sekiz köy bulunmaktadır. Yukarıda adı geçen köylerin bazıları göçler sebebiyle boşalmıştır. Göç öncesinde bölgede 70 kadar Türk köyü bulunmaktadır. Göçlerin 
sonucunda bölgede kültürel faaliyetler zayıflamış, nüfus sayısında azalma meydana gelmiştir (Uğurlu, 2015:39).

Çalıklı köyünün insanları Türk gelenek ve göreneklerini, inançlarını, el sanatlarını günümüzde yaşatmaya devam etmektedir. Bu geleneklerin arasında Hıdrellez kutlamaları bulunmaktadır. Hıdrellez kutlamaları “Uluslararası Bahar Şenlikleri” adıyla UNESCO’nun Dünya Kültür Mirası Listesi'nde yer almaktadır. Önceleri ulusal düzeyde olan festival daha sonra uluslararası düzeye taşınmış, Türkiye Cumhuriyeti Kültür ve Turizm Bakanlığı, Türk İşbirliği ve Koordinasyon Ajansı Başkanlığı, Güreş Federasyonu gibi kuruluşlar destek vermiştir (Ünver, 2010:129). 2019 yılında 28.'si düzenlenen festival, Çalıklı'nın kültürel değerlerini dünyaya tanıtması açısından önemlidir. Festivalde halk oyunları gösterileri, yarışmalar, sergi, sempozyum ve sportif faaliyetler yapılmaktadır. Aynı zamanda festival, Kuzey Makedonya'da yaşayan Türklerin bir araya gelerek sosyal bir ortamda buluşmalarına, tanışmalarına olanak tanımaktadır (Nasrattınoğlu, 2015:189).

Çalıklı köyünde halk çeşitli el sanatlarıyla zamanını değerlendirmekte, günlük eşya olarak ihtiyaçlarını karşılamaktadır. Çeyiz hazırlığında el sanatları önemlidir. El örgüsü patikler, çeşitli işlemeler, el dokuması kumaşlar, kumaşlardan dikilmiş göynek, çarşaf ve el dokuması kilimler geleneksel sanatlar içinde bulunmaktadır. Kilim dokumaları yaygı (Görsel 1), yük örtüsü, heybe, torba olarak kullanılmaktadır.

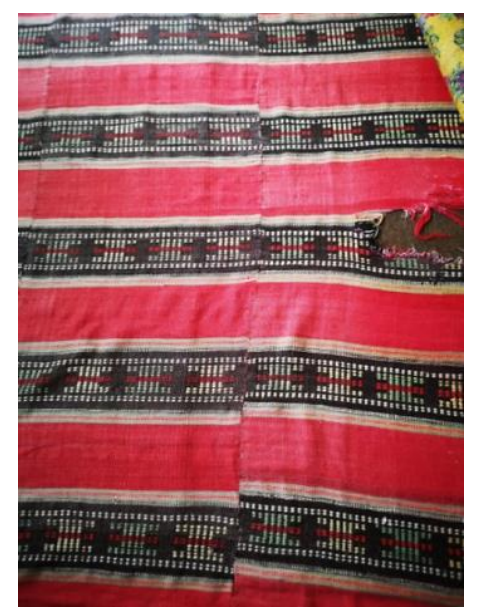

Görsel 1. Çalıklı Camisi'nde serili kilimin çözgü ve atkı ipliği yün, ebadı 150 cm×220 cmdir. Üç parça dokunan kilim birleştirilmiştir. Dokumada sökülmeler mevcuttur. 
Günlük kullanım amacıyla üretilen el sanatlarında eskiyen malzemeler değerlendirilmektedir. Bu el sanatları içinde daha çok çaput kilim adıyla bilinen, yörede ise partal kilim, çerge kilim denilen dokumalar başta gelmektedir. Partal kilim, çerge kilim, çaput kilim; eski kumaşların şerit haline getirilerek çulfalık tezgâhta dokunmasıyla oluşturulan kilimdir. Partal, sözlükte "Çok kullanılmaktan yıpranmış" tanımlamasına sahiptir (Oksal, 1964:306).

Çalıklı el sanatları arasında önemli bir yere sahip olan çarşaflık dokumaların günümüzde üretimi azalmış, dokumayı bilen usta sayısında düşüş meydana gelmiştir. Günümüzde köyde dokuma tezgâhını kurarak geleneksel yöntemle kumaş dokuyan usta Türkan Zulfikarova'dır. Diğer evlerde dokuma yapılmamaktadır. 1961 yılında Bahçebosu köyünde dünyaya gelen Zulfikarova, Çalıklı köyüne gelin gelmiş ve kumaş dokuma sanatının inceliklerini kayınvalidesi Ratibe Zulfikarova'dan öğrenmiştir. Ratibe Zulfikarova 1935 yılı Pıristan doğumludur. Türkan Zulfikarova'nın annesi Cemile Veysel'de Bahçebosu köyünde halen geleneksel el dokuması kumaş üretmektedir. Cemile Veysel 1936 yılı Bahçebosu köyü doğumludur. Türkan Zulfikarova'da kumaş dokuma sanatını gelini Pembe Zulfikarova'ya öğretmiştir. Gökçeli köyü doğumlu olan Pembe Zulfikarova, kayınvalidesi Türkan Zulfikarova ile birlikte çarşaflık kumaş dokumaktadır.

Annenin kızına, kayınvalidenin gelinine öğrettiği, ipliğin hazırlanmasından dokuma işlemine kadar özverili çalışma gerektiren ata sanatının, kültür mirası içinde ki yeri göz ardı edilemeyecek kadar önemlidir. Her kuşakta, temel teknik bilgileri kaybetmeden gelişen dokuma sanatı kültür birikimidir. Araştırmanın amacını Türk kültüründe önemli bir yere sahip olan kumaş dokuma sanatını, Kuzey Makedonya/Valandova/Çalıklı köyünde yaşatan, Türkan Zulfikarova'nın dokuduğu örnekler ışığında yörenin dokuma özelliklerinin, üretimde kullanılan hammaddelerin, araç ve gereçlerin, uygulanan yöntemlerin, dokumaya ait terimlerin tespit edilmesi oluşturmaktadır. Son yıllarda, Balkan ülkelerinden çeşitli sebeplerle yapılan göçler bu yerleşim bölgelerinde yaşayan insanların nüfusunu azaltmış, sadece insanların göçü değil kültür göçü de meydana gelmiştir. Yapılan literatür taramasında Çalıklı köyü çarşafık kumaş dokumalarıyla ilgili bir araştırmaya rastlanmaması, tespit edilen bilgilerin yazılı kaynak haline 
getirilmesi ve geleneksel kumaş dokuma ile ilgili çalışma yapacak bilim insanlarına kaynak olması araştırmanın önemini artırmıştır.

\section{Materyal ve Metot}

Araştırmanın materyalini Kuzey Makedonya/Valandova'nın Çalıklı köyünde yaşayan dokuma ustası Türkan Zulfikarova'nın geleneksel yöntem ile el tezgâhında dokuduğu çarşaflık kumaşlar oluşturmaktadır. Konu "Kuzey Makedonya-Valandova-Çalıklı Köyünde Türkan Zulfikarova'nın Dokuduğu Çarşafık Kumaşlar" olarak sınırlandırılmıştır. Araştırmanın metodunda nitel araştırma yöntemlerinden alan araştırması, literatür taraması kullanılmıştır. 10 adet çarşaflık dokuma kumaş örneği incelenmiş, benzer özellikler göstermesi nedeniyle 5 adedinin görseline yer verilmiştir. Araştırmada el dokuması çarşaflık kumaşların hammaddesi, iplik türü tespit edilmiş, eni ve boyu ölçülmüş, fotoğraflanmıştır. Görsellerin kaynaklarına makalenin sonunda bulunan kaynakçada yer verilmiştir. Ayrıca çözgü, atkı sıraları sayılmış, renk, desen özellikleri belirlenmiştir. Alan araştırması 01-07 Mayıs 2019 yılında, literatür taraması 2019 ve 2020 yılları arasında yapılmış, dokuma tekniğinin çiziminde üç boyutlu modelleme "Blender programı" kullanılmıştır. Elde edilen veriler bulguları oluşturmuş, araştırmanın sonuçları değerlendirme kısmında sunularak, geleneksel el dokuması çarşaflık kumaşların üretimine yönelik önerilerde bulunulmuştur.

\section{Bulgular}

\section{1. Çalıklı'da Geleneksel Kumaş Dokuma Kültürü, Çarşafık Dokumalarda Kullanılan} Malzemeler

İnsanların örtünme, korunma ihtiyacı ile ortaya çıkan dokumacılık, Türk kültüründe de önemli bir yere sahiptir. Kaşgarlı Mahmud'un Dîvânü Lugati’t Türk'de "Böz tokıdı, böz tokıldı", "Bez dokudu, bez dokundu", "Sedrek böz", "Seyrek dokunmuş bez", “Ol böz yügürdi”, "O kumaşın çözgüsünü hazırladı" ifadeleri yer almaktadır (Ercilasun ve Akkoyunlu, 2015:208, 379).

Kumaş, liflerin ve ipliklerin çeşitli tekniklerle birbirine bağlanmasıyla oluşturulan tekstil ürünleridir. Çeşitli hammaddelerden farklı yöntemlerle kumaş yüzeyi oluşturulabilir. Elde edilen 
kumaşların yüzey düzgünlüğü, kalınlığı, esnekliği, sağlamlı̆̆ı gibi çeşitli özellikleri bulunmaktadır (Sarığlu vd., 2011:20).

Evlerde kumaş dokumacılığı önceleri kadınlar tarafından ev halkının ihtiyacını gidermek amacıyla yapılmıştır. Hayvancılık ve tarımla uğraşan insanlar elde ettikleri yapağıyı, pamuğu, keteni eğirerek iplik haline getirmiş dokumaların hammaddesini oluşturmuştur (Salman, 2004:14).

Çalıklı köyünün eski dokumalarında yünün ve pamuğun elde eğirilmesiyle üretilen iplikler kullanılmış bu kumaşlardan iç giyim, gergi, çarşaf, başörtüsü, gömlek, don, pantolon dikilmiştir (Zulfikarova T., 2019). Türklerde iplik eğirme kültürü ile ilgili bilgiler yazılı kaynaklarda karşımıza çıkmaktadır. Kaşgarlı Mahmud'un Dîvânü Lugati't Türk'de "Kız anası birle yıp egrişti”, "Kız ip eğirmekte annesiyle yarıştı”, "Yıp eğrildi”, "ip eğrildi”, "Ura gut yıp egirisedi”, "Kadın ip eğirmek istedi", "Tawratmış yıp", "Kıvrık hale getirilmiş ip" ifadeleri yer almaktadır (Ercilasun ve Akkoyunlu, 2015:110, 114, 132, 346).

Eğirilecek hammadde önce üzerinde bulunan yabancı maddelerden arındırılıp, yıkanıp, taranmaktadır. Daha sonra iplik olması için eğirme işlemine geçilmektedir. Çalıklı'da ipliğin eğirilmesi işleminde kullanılan başlıca aletler arasında fırtışka ve çıkrık bulunmaktadır.

Fırtışka (Gülcan): Gelep denilen iplik çilelerinin birbirine karışmaması için kullanılan, ahşaptan yapılmış en basit haliyle iki çerçevenin iç içe geçmesiyle oluşturulmuş bir alettir (Görsel 2). Kendi etrafında dönerek iplik çilelerinin yumak yapılmasını sağlamaktadır. Fırtışkanın her bir köşesine gelebin düşmemesi için kumaş parçaları top haline getirilerek bağlanmaktadır. Üzerine takılan iplik çilelerinin çıkrıkta masuraya sarılması için kullanıldığı gibi ipliklerin iki kat sarılmasına imkân tanımaktadır. Iki kat olması istenen iplikler birleştirilip büküm verilerek çıkrıkta ki masuraya sarılmaktadır (Zulfikarova T., 2019). 


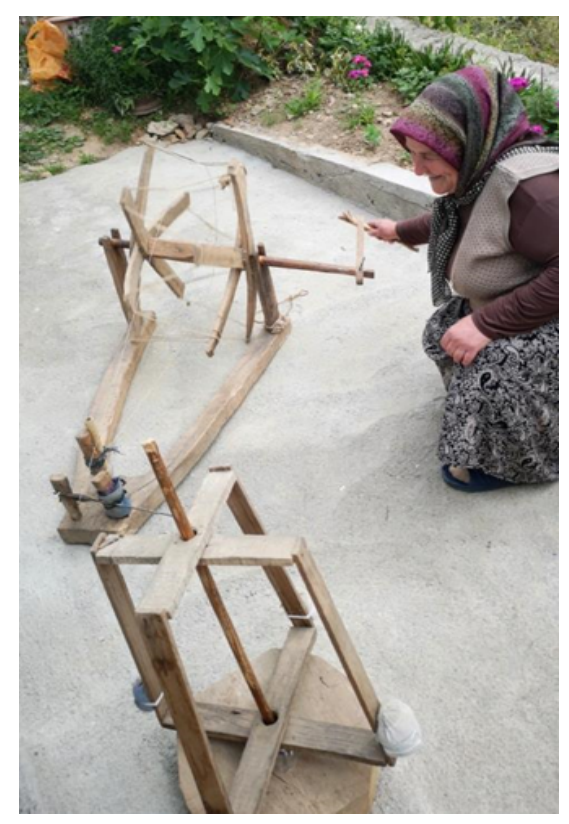

Görsel 2. Fırtışka ve Çıkrık. Türkan Zulfikarova çıkrığının başında görülmektedir.

Çıkrık: Pamuk ya da yünün eğirilmesiyle oluşan ipliğin masuraya sarılmasına aynı zamanda gülcana takılan geleplerin açılmasıyla boşa çıkan ipliklerin masuraya sarılmasına yarayan alete denilmektedir (Görsel 2). Ahşaptan yapılan çıkrığın birçok çeşidinin bulunmasına rağmen çalışma prensibi aynıdır. Çıkrığın dolabını insan gücüyle döndürmeye yarayan yatay bir çubuğa bağlı kol ve bu düzenin bağlı olduğu iği çevirmeye yarayan ip, ipi döndüren çark temel parçalardır. Çıkrığın ucunda masuranın takıldığı iğ bulunmaktadır. İği, çıkrığa takılmış sürekli dönen bir iplik çevirmektedir. Dönen bu ipliğin sağlam kalması, kopmaması, rahat dönebilmesi için iğin, ipliğe temas eden uç kısmına katran sürülmektedir (Zulfikarova T., 2019). Katran, maden kömüründen çıkarılan koyu, ağır is kokulu ve siyah bir sıvıdır (Oksal, 1964:194).

Çalıklı köyünde önceden pamuk ve yünün eğirilmesiyle elde edilen iplikler dokuma ve örgü işlerinde kullanıırken, günümüzde hazır ipliklerde kullanılmaktadır. Ekonomik güçlükler tasarruf yönü kuvvetli olan Çalıklı insanını harekete geçirmiştir. Köyün geçim kaynakları arasında bulunan tütün üretimi geri dönüşüm olgusunu etkilemiştir. Özellikle tütün çuvallarının ağzını bağlamakta ve tütün dizmekte kullanılan pamuk ipliklerinin bazı işlemlerden geçirilerek çarşaflık dokumalarda kullanılması geri dönüşüm konusunda önemli bir olgudur. Dokuma yapılacak zamanın belirlenmesinde tütün dizi ipliklerinin biriktirilmesi, yeterli miktarda çözgü ve 
atkı ipliğinin elde edilmesi etken rol oynamaktadır. Yeterli miktarda iplik elde edildiğinde tezgâh kurulmaktadır. Bu biriktirme bir ya da iki yıl sürmektedir (Zulfikarova P., 2019). Türkan Zulfikarova çarşafık dokumalarında biriktirdiği tütün dizi ipliklerini kullanmayı tercih etmektedir.

Geri dönüşümü, kullanılmış malzemelerin geri kazanılabilecek özellikte olanlarının farklı tekniklerle yeniden üretim sürecine katılması olarak tanımlayabiliriz (Türemen vd., 2019:805). Yapılan araştırmalar, özellikle tekstildeki dönüşümün ekonomiye katkısı küçümsenmeyecek kadar önemli olduğunu göstermektedir. Tekstil üretiminde ortaya çıkan ve kullanım sonrası oluşan atıkların yeniden değerlendirilmesi, diğer sektörlere göre daha kolaydır. Çünkü değerlendirme alanı geniştir. Tekstil alanında ortaya çıkan atıkların tekrar değerlendirilmesi ekonominin döngüsel yaklaşımına uygun görülmektedir (Macit vd., 2019:92).

Tütün bitkisinin anavatanının Amerika kıtası olduğu ve buradan dünyaya yayıldığı tahmin edilmektedir. Osmanlı zamanında, tütünün tohumu Rumelili tüccarlar tarafından Avrupa'dan getirilerek ilk defa yetiştirilmesine Kuzey Makedonya, Yenice ve Kırcaali'de başlandığı kaynaklarda belirtilmektedir. Tütün tarımının bu yerleşim birimlerinde yaygınlaşmasının ardından Anadolu'ya getirilerek üretimi devam etmiştir (Karabacak, 2017:28). Çalıklı köyünün önemli geçim kaynakları arasında bulunan tütün üretiminde tütünün yetiştirilmesi, kırımı, dizimi, satımı önemli işlem basamakları arasında bulunmaktadır. Kırılan tütünler pamuk ipliklerine dizilerek güneşte kurutulmakta, kışın tütünler diziden çıkarılıp sandıklara basılmaktadır. Tütün dizilerinin iplikten sıyırılmasıyla geriye kalan doğal pamuk ipliklerinin değerlendirilmesi fikri ortaya çıkmıştır. Uzun kış gecelerinde hem bu iplikler hem de zaman değerlendirilmektedir (Zulfikarova T., 2019).

Tütünlerin dizildiği pamuk iplikleri öncelikle tütünlerden ayrılıp biriktirilmektedir. Daha sonra ılık suda yıkanıp kurutulmakta ve dokuma için hazırlanmaktadır. Dokumalarda tütün dizi iplikleri kullanıldığı için bu çözgü ve atkı ipliklerine haşıllama işlemi yapılmamaktadır. Bir tütün dizisi için 5 metre iplik kullanılmaktadır. "S" bükümlü, dört katlı ve \%100 pamuktan üretilmiş iplikler çözgü ipliği olarak hazırlanırken, çözgü uzunluğunun 20 metre olması için 4 dizi ipliği üç düğümle birleştirilerek uzatılmaktadır (Görsel 3). Ayrıca 4 katlı ipliklerin 2 katı ayrılıp atkı ve 
çözgüde 2 katlı olarak kullanılmaktadır. Bu ipliklerin numarası Ne 7'dir. Tütün dizisi ipliklerinin rengi beyaz olduğu için çözgü ve atkı renginde genellikle beyaz tercih edilmektedir. Aralara konulan yatay bant desenlerinde renkli pamuk iplikleri kullanılmaktadır (Tablo 1). İpliklere boyama işlemi yapılmamakta, renkli iplikler hazır alınmaktadır. Bazı çarşaf dokumalarında 2 katlı olan tütün dizi ipliğinin 2 katı ayrılarak tek katlı yapılmakta, ayrılan bu iplik tek katlı renkli iplikle birleştirilerek bükülmekte, böylece ipliğe hareket kazandırılmaktadır (Zulfikarova P., 2019). Kumaşlara renk vermek Türklerde eskiden de sevilmiş, iki renkli iplikler XI. yy. da kaplana benzetilerek Türk diyarında "Asrı yışı̆̆" denilmiştir (Genç, 1997:10).

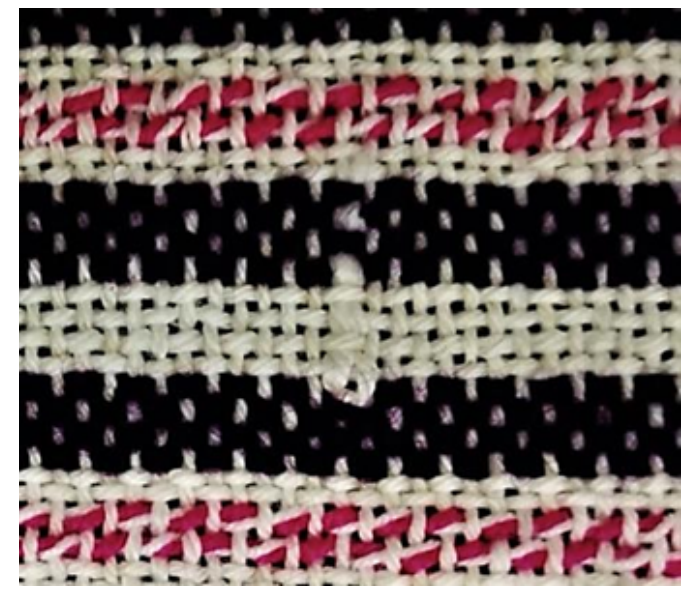

Görsel 3. Çözgü ipliklerinin birbirine eklenmesi ve farklı renk ipliklerin birbirine dolanmasıyla elde edilen desen hareketi.

Tablo 1. Çarşaflık Kumaşların Dokunmasında Kullanılan Atkı ve Çözgü İpliklerinin Özellikleri.

\begin{tabular}{|l|l|}
\hline Çözgü ve atkı ipliklerinin hammaddesi & Pamuk \\
\hline Çözgü ve atkı ipliklerinin büküm yönü & $\mathrm{S}$ \\
\hline Çözgü ve atkı ipliklerinin kat sayısı & 2 \\
\hline Çözgü ve atkı ipliklerinin numarası & Ne 7 \\
\hline Çözgü ipliklerinin renkleri & Doğal pamuk ipliği rengi \\
\hline Atkı ipliklerinin renkleri & $\begin{array}{l}\text { Doğal pamuk ipliği rengi, kırmızı, kahverengi, lacivert, mavi, sarı, } \\
\text { yeşil, pembe, mor }\end{array}$ \\
\hline
\end{tabular}




\subsection{Tezgâh ve Dokumaya Hazırlık}

Anadolu'da farklı yörelerde culhalık, çulfalık, mekikli tezgah, düzen, ayakcaklı tezgah denilen, Balkanlarda ise "Mutaf tezgâhı" adıyla anılan kumaş tezgâhı (Soysaldı, 2009:17), Çalıklı köyünde "Düzen", "Tezgâh", adıyla bilinmektedir (Zulfikarova P., 2019). Türk Dil Kurumu sözlüğünde mutaf kelimesi Fars kökenli olduğu belirtilerek "Keçi kılından hayvanlar için dokunan çul, yem torbası gibi malzemeleri dokuyan kimse" tanımlamasına sahiptir (tdk.gov.tr, 27.04.2020).

Geleneksel kumaş dokuma tezgâhı (Çulfalık tezgâh), günlük kullanım için dokunacak desenli, desensiz kumaşların ya da giyimlik üretilecek olan yünlü, pamuklu kumaşların dokunmasında kullanılmaktadır. Bu tezgâhlar genellikle iki gücülü ve iki ayaklı, basit düzeneğe sahip bez dokuma tezgâhlarıdır. Eski tezgâhlarda gücüler bükümü yoğun, dayanıklılığı yüksek pamuk ipliğinden, tarak dişleri ise kamıştan yapılmış örnekleri bulunmaktadır. Günümüzde gücü ve tarak dişlerinin tel olması tercih edilmektedir (Soysaldı, 2009:17).

Çulhalık tezgâhının çalışma sisteminde, ayaklarla çözgü ağııının açılması, bu açılan ağızdan atkı ipliğinin takılı olduğu mekiğin geçirilmesi, tekrar ayaklarla ağızın açılıp çözgülerin yerinin değişmesiyle bir sonraki dokuma sırasına geçilip mekiğin diğer tarafa atılması, böylece dokumanın oluşturulması, atkı sıralarının tefe ile sıkıştırılarak dokuma işleminin devam etmesi bulunmaktadır. Çulhalık tezgâhın parçalarının genel anlamda adı ve Çalıklı köyünde bu parçalara verilen isimler şu şekildedir:

Krosna: Tezgâhın hem önünde hem de arkasında bulunan iki adet, yatay ahşap sargı leventleridir. Bu leventler silindir şeklinde, tezgâha takılıp, çıkartılabilen parçalardır. Arka krosnaya çözgü ipleri sarılır ve dokuma ilerledikçe çevrilerek çözgü iplerinin serbest bırakılması sağlanır. Ön krosnanın dokumanın eni kadar genişliğinde ve dokunan kumaşın başlangıcında bulunan çözgü ipliği kısmının sağlam olması için içinden geçirilerek sarıldığı bir yarık bulunmaktadır. Kumaş dokuması ilerledikçe dokunan kısım ön krosnaya sarılmakta, arka krosna gevşetilerek çözgü iplikleri dokumaya gönderilmektedir. Tezgâhın üretiminde çam ağacı tercih edilmektedir (Zulfikarova P., 2019). 
Çakara (Makara): Çalıklı'da geleneksel dokuma kumaş tezgâhının parçalarından birisidir. Gücülerin hareket etmesi için bağlanan iplerin pedala basılmasıyla yükselmesini sağlayan tezgâhın üstünde bulunan makaradır. Çakara tezgâhta iki adet bulunmaktadır. Çakara oynadıkça üzerinde gücünün hareket etmesi için bağlı olan iplik hareket eder ve ağızlık açılarak, atkı ipliğinin geçmesine olanak tanır. Böylece dokuma gerçekleşmektedir (Zulfikarova P., 2019).

Gücü ve gücü çerçeveleri: Çalıkı'da dokuma tezgâhlarında gücü çerçeveleri ahşaptan, gücü iplikleri pamuk ipliğinden oluşturulmaktadır. Gücüler ahşap iki ince silindir üzerine yapılmaktadır. Dokuma tezgâhında iki adet gücü bulunmakta, bunlara ön ve arka gücü denilmektedir. Gücülerin fonksiyonu, yükselerek ağızlığı açmak ve atkının diğer tarafa geçmesini sağlamaktır.

Tefe ve tarak: Dokuma tezgâhının önemli parçaları arasında olan tarak, ahşaptan yapılmış çerçevenin içine geçirilerek kullanılmaktadır. Bu çerçeveye tefe adı verilmektedir. Tefe ve tarağın kullanım amaçları arasında ilk olarak çözgünün eşit aralıklarla, düzgün bir şekilde sıralanmasını sağlamak, kumaş enini ayarlamak bulunmaktadır. Tefenin bir diğer önemli görevi, atılan atkının sıkıştırılması işlemidir (Soysaldı, 2009:18). Her sıra atkıdan sonra tefe vuruşuyla atkı ipliğinin kumaşa oturması sağlanmaktadır. Dokuyucunun kumaşa her sırada tefe vuruşunu eşit derecede yapması gerekmektedir. Aksi takdirde kumaş yüzeyinde eşit sıklık ve görünüm elde edilmemektedir.

Ayaklık: Geleneksel dokuma kumaş tezgâhlarında genellikle iki adet ayaklık bulunmaktadır. Bu ayaklıklara sağ ve sol ayaklık adı verilmektedir. Ayaklığa basıldığında, makaralara takılı olan iplerin çekilmesi ve makaraların (Çakara) bağlı olduğu gücünün hareket ederek yükselmesi sağlanmaktadır. Tezgâhlarda genellikle iki ayaklık, iki makara bulunmaktadır. Mekik sağdayken sağ ayaklığa, mekik soldayken sol ayaklığa basılmaktadır. Böylece ağızlık açılarak atkı karşıya geçmektedir. Sağ ayak arka gücüyü, sol ayak ön gücüyü kaldırmaktadır. Ayaklığın; düz, yassı ahşap ve tek pedal olduğu tezgâh örnekleri bulunmaktadır. Bu tezgâhlarda tek pedalın sağına basıldığında makaraya bağıı bir gücü çerçevesi, soluna basıldığında diğer makaraya bağlı gücü çerçevesi yükselerek ağızlığı açmaktadır (Zulfikarova P., 2019). 
Mekik: Kumaş dokuma tezgâhında atkı ipliklerinin açılan çözgüler arasından geçirilmesini kolaylaştıran alete verilen isimdir. Mekik, açılan çözgü ağızlığından rahat geçebilmesi için şekli yassı, uç kısımları sivridir. Yan tarafında ipliği salan bir deliği bulunmaktadır. Atkı karşıya geçirilmesi esnasında bu iplik gelen kısmı dokuyucuya bakacak şekilde tutulmaktadır. Atkı ipliği önce masuraya sarılmaktadır. Masura, içi boş silindir şeklindedir. Masuranın mekiğin içine yerleştirilebilmesi için mekikte bir yuva bulunmaktadır. Masuranın takıldığı mekik, açılan ağızlıktan atkı ipiyle karşı tarafa geçirilerek dokuma ilerletilmektedir. Çalıklı'da masuraya kalem denilmektedir.

Çimbar (Cumbar): Kumaş dokumanın eninin sabit ölçüde kalmasına yardımcı olan demir çubuktur. Çimbarın eni dokumanın enine göre kemer gibi ayarlanmaktadır. Dokuma kumaş tefeye yaklaştığında çimbar çıkarılıp arka krosna (Levent) gevşetilerek çözgü salınmakta, ön krosna sarılarak dokunan kumaşın yerine çözgü kısmı getirilmekte, çimbarın yeri değiştirilmektedir. Çimbar, kumaşın çözgünün başlama noktasına yakın kısma yerleştirilerek eni ayarlanmaktadır (Zulfikarova P., 2019).

Dokuma işlemine geçmeden önce kumaş yapımının ilk işlemi çözgünün hazırlanmasıdır. Dokuma tezgâhının ebatlarına ve özelliklerine uygun bir düzende çözgü hazırlanmaktadır. Çözgü hazırlama işlemine "Çözgü çekme" denilmektedir (Yılmaz ve Anmaç, 2000:9). Çalıklı köyünde çözgü düz alanda hazırlanmaktadır. Tarağı ve gücü enine göre çözgünün tel sayısı hesaplanmaktadır. Çözgünün uzunluk ölçüsüne yörede "Lakıt" denilmektedir. 1 lakıt 65 cm'dir. Bir ölçü birimi olan ama günümüzde kullanılmayan "Endaze" ölçüsü de her bir 65 santimetreyi ifade etmektedir (Oksal, 1964:112). Lakıt ifadesi, endazeyi işaret etmektedir. $75 \mathrm{~cm}$ en için 450 adet çözgü teli hazırlanmaktadır. Çözgü, dokumanın eni ve boyu hesaplanarak iplik tedarik edilmekte ve toprağa çakılan kazıkların aralıkları bu ölçülere göre ayarlanmaktadır. Çözgü atımının başlamasında ve dönüşlerde kazığa atılan iplik düğümünün krosnanın kalınlığı kadar boşluk oluşturulmasına dikkat edilmektedir. Aksi halde çözgü ipliklerinin krosnaya takılması esnasında kopmalar meydana gelmektedir. Çözgü ipliklerinin kazıklardan çıkartılmasından önce çaprazın bozulmaması için iki çözgü aralığından ağızlık ipi geçirilmektedir. (Zulfikarova T., 2019). 
Çözgü ipliklerinin uzunluğu $20 \mathrm{~m}$ ya da $25 \mathrm{~m}$ ayarlanmaktadır. Çarşafların boyu $188 \mathrm{~cm}$ olduğu için çözgünün boyuna göre yaklaşık 10-12 parça çav elde edilmektedir. Çav, çarşafı oluşturan parçaların her birine denilmektedir. 1 çav $75 \mathrm{~cm}$ x 118 cm'dir. Çözgü çekme işlemi bittikten sonra kazıklardan alınan iplikler tezgâha takılmaktadır. Tezgâha aktarım işleminde arka krosnaya sarılan çözgü iplikleri gücülerden geçirildikten sonra, tefeye takılı olan tarakların arasından alınarak ön krosnaya sarılmaktadır. Gücü ipliklerinden elle geçirilen çözgü ipliklerinin sıralamasına dikkat edilmektedir. Gücü telleri pamuk ipliğinden yapılmışsa çözgü iplikleri el ile gücü telleri metalden ise çözgü iplikleri tığ ile gücü gözlerinden alınarak tarak işlemine hazırlanmaktadır. Gücüden geçirilen çözgü iplikleri tarağa geçirilirken, tarağın her metal teli atlanmadan tığ ile çözgü iplikleri arkadan öne geçirilmektedir. Tarak dişinden 1 adet çözgü teli geçirilmektedir. Gücülerden çözgülerin geçirilmesi işleminde dikkat edilmesi gereken bir hususta çerçevelere çözgülerin geçirilme sırasıdır. Ağızlığın açılarak, atkı ipliğinin bir üst, bir alttan geçebilmesi için çözgülerin plana göre çerçevelerden geçirilmesi gerekmektedir. Gücülerden ve taraktan geçirilen çözgü iplikleri ön krosnaya bağlanmaktadır. Çözgü işleminin bir diğer basamağı, çözgü çaprazının bozulmaması için arka krosnaya yakın çözgüye çapraz çubuklarının takılarak dokumaya hazırlığın tamamlanmasıdır. Ahşap malzeme taşınması, kurulması metal malzemeye göre kolay olduğu için dokuma tezgâhının yapımında tercih edilmiştir (Zulfikarova P., 2019).

\section{3. Çarşaflık Kumaşlarda Dokuma Tekniği ve Kumaş Özellikleri}

Çalıklı köyünün geleneksel kumaş dokumalarında temel ve basit kabul edilen "Bezayağı” tekniği uygulanmıştır. Bezayağı bütün kumaş dokuma teknikleri içinde en çok uygulanan tekniktir. Türkan Zulfikarova'nın dokuduğu geleneksel çarşafık dokuma kumaşlarda da bezayağı tekniği uygulanmıştır. Farklı hammaddelerden oluşan iplik türleriyle hafif kumaşlardan, en ağır kumaş çeşitlerine kadar yaygın uygulama alanına sahiptir. Bezayağı tekniği uygulanmış kumaş dokumalarının çözgü, atkı ipliği aynı numarada ve sıkıkta kullanıldığında her iplik bağlandığı diğer ipliklerin üstünde ve altında aynı ölçüde yol alarak kıvrılmaktadır (Yılmaz ve Anmaç, 2000:26) (Görsel 4). 
Bezayağı dokuma tekniği kullanılan kumaşların tersi ve yüzü aynı görünüme sahiptir. Atkı ve çözgü iplikleri aynı gerginlikte oldukları için kumaşın yüzeyi de düzgün görünmektedir. Türkan Zulfikarova'nın çarşaflık kumaş dokumaları incelendiğinde çözgü ve atkı ipliklerinin aynı kalınlıkta ve gerginlikte olduğu tespit edilmiştir. Kumaşın yüzeyi düzgündür. Çözgü ve atkı iplikleri rahatlıkla sayılmaktadır. Yörede dokuma tekniğinin adı sorulduğunda sadece "Dokuma" denilmiştir (Zulfikarova T., 2019).

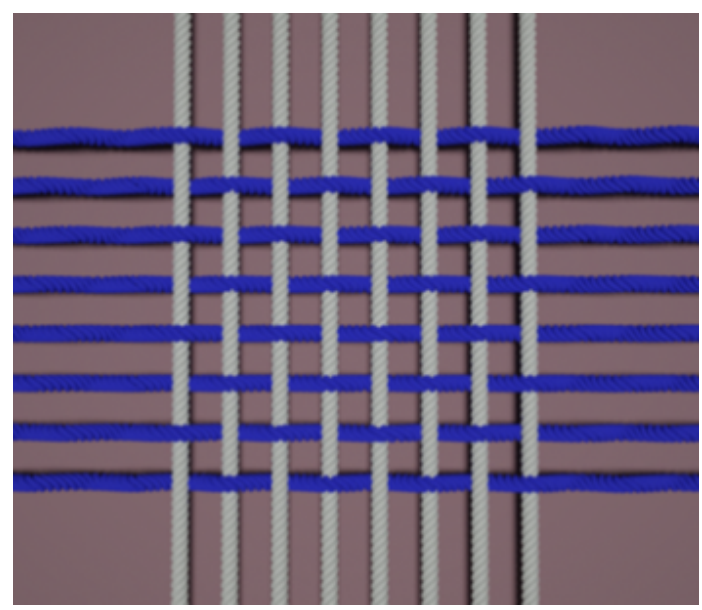

Görsel 4. Bezayağı dokuma tekniğinin çizimi. Çözgü ipliği; beyaz, atkı ipliği; mavidir.

Zulfikarova'nın çarşaflık dokumalarında çözgü $6 \mathrm{~cm} / \mathrm{sıklık,} \mathrm{atkı} 8 \mathrm{~cm} / \mathrm{sıklık}$ bulunmaktadır. $75 \mathrm{~cm}$ enindeki dokumada 450 adet çözgü teli, $188 \mathrm{~cm}$ boyunda ki dokumada 1504 adet atkı sırası bulunmaktadır.

Kumaş dokumalarının eni dokuma tezgâhının enine bağııdır. Tezgâhtan çıkan kumaşların eni $75 \mathrm{~cm}$ 'dir. $75 \mathrm{~cm}$ x $118 \mathrm{~cm}$ ebatlarında 1 çav normal şartlarda iki günde dokunmaktadır. Tezgâhta bulunan kumaş dokuma işlemi tamamlandığında $75 \mathrm{~cm} \times 20 \mathrm{~m}$ ebatlarında kesilip dikilmeye hazır çarşaflık kumaş elde edilmektedir (Görsel 5). 


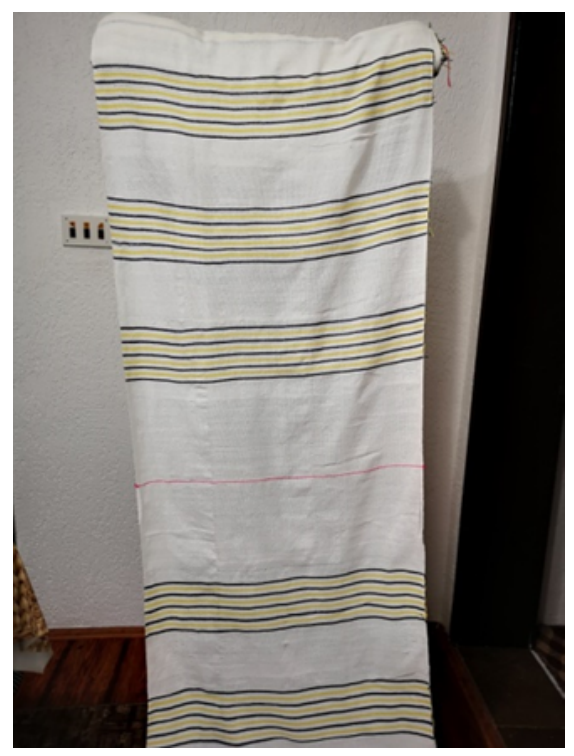

Görsel 5. Eni $75 \mathrm{~cm}$, Boyu 20 m olan tezgâhtan çıkarılmış çarşaflık dokuma kumaş.

Dokuma esnasında bir çavın standart boy ölçüsü olan 188 cm'ye gelindiğinde kırmızı iplikle bir sıra atkı atılarak boy uzunluğu işareti bırakılmakta ve dokumaya devam edilmektedir. Dokuma aynı uzunluk ölçüsüne geldiğinde tekrar kırmızı iplikle işaret konulmaktadır. Dokuma, tezgâhtan çıkarıldığında bu kırmızı işaretin olduğu yerden kesilerek parçalar elde edilmektedir (Görsel 6).

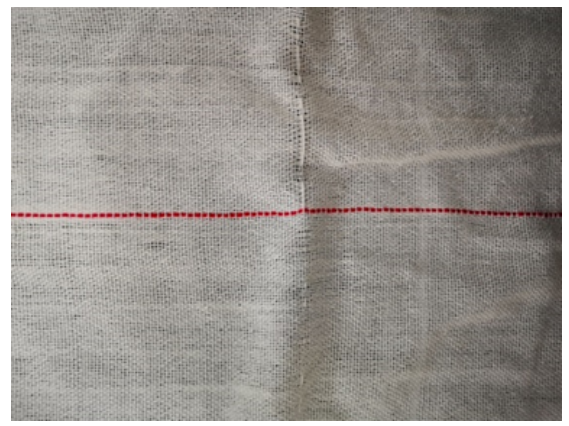

Görsel 6. Dokumanın $188 \mathrm{~cm}$ uzunluğuna, bir çarşaflık boya geldiğini işaretleyen kırmızı atkı.

Çarşafık dokumalar, tek kişilik ya da çift kişilik olmasına göre çavları birleştirilmektedir. Tek kişilik çarşaflık kumaşlar için iki çav birleştirilerek $150 \mathrm{~cm}$ en elde edilmektedir. Tek kişilik çarşaflar $150 \mathrm{~cm}$ x $188 \mathrm{~cm}$ ebatlarındadır. Çift kişilik çarşaflar için 3 çav birleştirilerek $225 \mathrm{~cm}$ en elde edilmektedir. Çift kişilik çarşaflar $225 \mathrm{~cm}$ x $188 \mathrm{~cm}$ ebatlarındadır (Tablo 2). 
Tablo 2. Çarşaflık Kumaş Dokumalarının Teknik Özellikleri.

\begin{tabular}{|l|l|}
\hline Dokuma tekniği & Bezayağı \\
\hline $\mathbf{1}$ cm eninde bulunan çözgü sıklığı & 6 \\
\hline $\mathbf{1}$ cm boyunda bulunan atkı sıklığı & 8 \\
\hline $\mathbf{1}$ çavın eni & $75 \mathrm{~cm}$ \\
\hline $\mathbf{1}$ çavın eninde bulunan çözgü sıklığı & 450 \\
\hline $\mathbf{1}$ çavın (188cm) boyunda bulunan atkı sıklığı & 1504 \\
\hline Tek kişilik çarşafta kullanılan çav adedi & 2 \\
\hline Tek kişilik çarşafın ebatları & $150 \mathrm{~cm} \times 188 \mathrm{~cm}$ \\
\hline Çift kişilik çarşafta kullanılan çav adedi & 3 \\
\hline Çift kişilik çarşafın ebatları & $225 \mathrm{~cm} \times 188 \mathrm{~cm}$ \\
\hline
\end{tabular}

Çarşaflık dokumaların zemininde beyaz kullanılırken aralıklı olarak enine renkli ipliklerden yatay bantlar oluşturulmaktadır. Bu bantlarda lacivert, mavi, sarı, pembe, mor, bordo, yeşil kullanılmaktadır. Lacivert ile sarı, yeşil ile mor, kırmızı, yeşil, mavi, mor birlikte kullanıldığı gibi, bordo ile yeşil, kahverengi ile kırmızı birlikte kullanılarak yatay bantlar elde edilmektedir.

Dokuma işlemi tamamlanan kumaşlar tezgâhtan çıkarılmakta, kırmızı işaretli kısımlardan kesilmektedir. Kesilen kenarların sökülmemesi için elle bastırılmaktadır. Çarşafın tek kişilik ya da çift kişilik olmasına göre parçalar, birleşim yerinin arkada kalmasına dikkat edilerek dikilmektedir. Çeyiz olması amacıyla dokunan çarşaflık kumaşlar sandıkta korunmakta, hemen kullanılacak ise yıkama işleminden sonra yatağa serilmektedir.

\subsection{Türkan Zulfikarova'nın Dokuduğu Çarşaflık Kumaş Örnekleri}

Görsel 7. Örnek 1. Kullanım alanı: Çarşaf

Dokunduğu tarih: 2015

Boyutları: $150 \mathrm{~cm} \times 188 \mathrm{~cm}$. 
Kullanılan iplik: Atkı ve çözgü ipliği; pamuk iplik, çözgü sıklığı; $6 \mathrm{~cm} / \mathrm{sıklık,} \mathrm{atkı} \mathrm{sıklığı;} 8 \mathrm{~cm} / \mathrm{sıklık}$ Iplik numarası: Ne 7

Kompozisyon: 2 çav dokumanın birleştirilmesiyle olan tek kişilik çarşaf dokumanın zemininde beyaz, 13 yatay bandın oluşturduğu desende mavi, pembe, kırmızı, yeşil, dönüşümlü olarak kullanılmıştır. Her renk sırasına 2 atkı ipliği atılmış, çeyizlik amacıyla dokunmuştur.

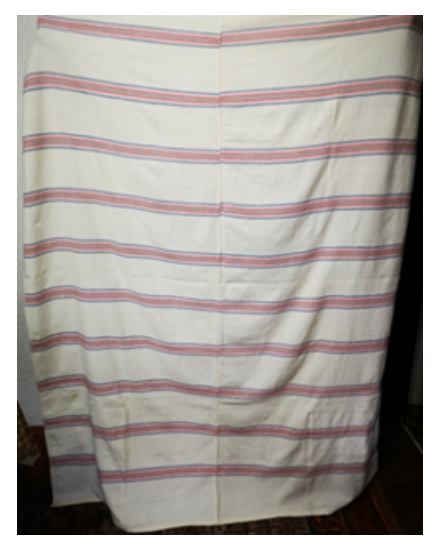

Görsel 7. Örnek 1. Türkan Zulfikarova'nın dokuduğu, iki çavın birleştirildiği, $150 \mathrm{~cm} \times 188 \mathrm{~cm}$ ebatlarında tek kişilik çarşaf.

Görsel 8. Örnek 2. Kullanım alanı: Çarşaf

Dokunduğu tarih: 2015

Boyutları: $225 \mathrm{~cm} \times 188 \mathrm{~cm}$.

Kullanılan iplik: Atkı ve çözgü ipliği; pamuk iplik, çözgü sıklığı; $6 \mathrm{~cm} / \mathrm{sıklık,} \mathrm{atkı} \mathrm{sıklığı;} 8 \mathrm{~cm} / \mathrm{sıklık}$ Iplik numarası: Ne 7

Kompozisyon: Çift kişilik çarşaf dokumanın zemini beyaz, 11 yatay bandın oluşturduğu desende lacivert ve pembe, beyaz dönüşümlü olarak kullanılmıştır. Pembe ipliğin beyaz ipliğe dolanarak büküm verildiği ipliğin kullanıldığı dokumada 4 sıra lacivert, 4 sıra beyaz, 2 sıra pembe atkı atılarak yatay bantlar oluşturulmuştur. 


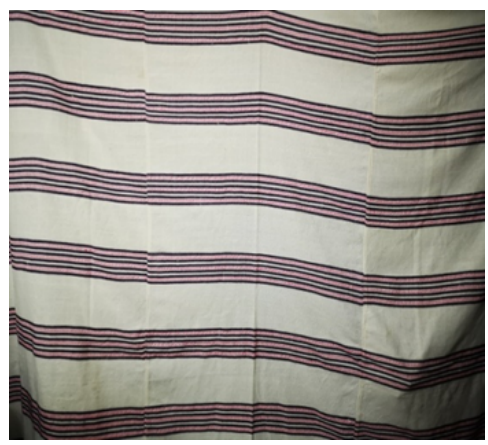

Görsel 8. Örnek 2. Türkan Zulfikarova'nın dokuduğu, üç çavın birleştirildiği, $225 \mathrm{~cm} \times 188 \mathrm{~cm}$ ebatlarında çift kişilik çarşaf.

Görsel 9. Örnek 3. Kullanım alanı: Çarşaf

Dokunduğu tarih: 2018

Boyutları: $75 \mathrm{~cm} \times 20 \mathrm{~m}$.

Kullanılan iplik: Atkı ve çözgü ipliği; pamuk iplik, çözgü sıklığı; $6 \mathrm{~cm} / \mathrm{sıklık,} \mathrm{atkı} \mathrm{sıklığı;} 8 \mathrm{~cm} / \mathrm{sıklık}$ Iplik numarası: Ne 7

Kompozisyon: Türkan Zulfikarova ve gelini Pembe Zulfikarova'nın birlikte dokudukları çarşaflık kumaşın tek ya da çift kişilik olmasına karar verilerek çav birleşimi yapılacaktır. Çarşaflık dokumadan 10 parça çav elde edilecektir. Dokumanın zemini beyaz, 17 yatay bandın oluşturduğu desende lacivert, sarı dönüşümlü olarak kullanılmıştır. Dokumada 4 sıra lacivert, 8 sıra beyaz, 4 sıra mavi atkı atılarak yatay bantlar oluşturulmuştur.

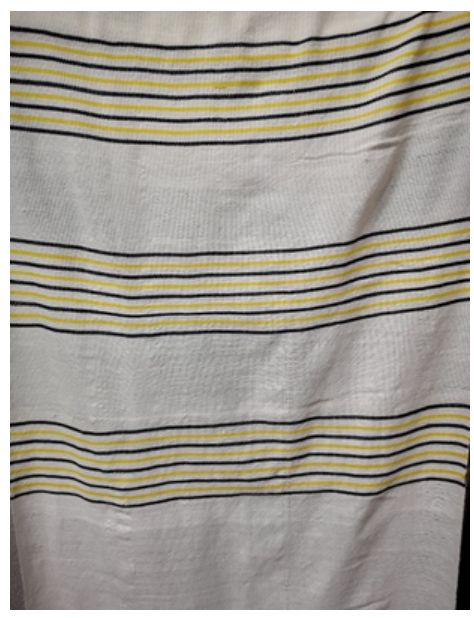

Görsel 9. Örnek $3.75 \mathrm{~cm}$ x 20 m olan çarşaflık kumaş. 
Görsel 10. Örnek 4. Kullanım alanı: Çarşaf

Dokunduğu tarih: 2018

Boyutları: $225 \mathrm{~cm} \times 188 \mathrm{~cm}$.

Kullanılan iplik: Atkı ve çözgü ipliği; pamuk iplik, çözgü sıklığı; $6 \mathrm{~cm} / \mathrm{sıklık,} \mathrm{atkı} \mathrm{sıklığı;} 8 \mathrm{~cm} / \mathrm{sıklık}$ İplik numarası: Ne 7

Kompozisyon: Türkan Zulfikarova'nın dokuduğu çarşaf 3 çav çarşafılı dokumanın birleştirilmesiyle oluşturulmuştur. Çift kişilik çarşaf dokumanın zemini beyazdır. 24 yatay bandın oluşturduğu desende bordo, yeşil, beyaz dönüşümlü kullanılmıştır. Dokumada 3 sıra bordo, 2 sıra yeşil, 2-4 arasında beyaz atkı atılarak yatay bantlar oluşturulmuştur.

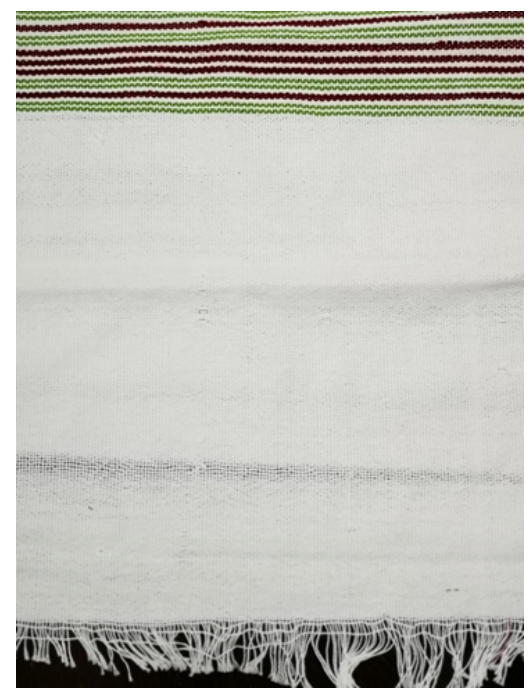

Görsel 10. Örnek 4. $225 \mathrm{~cm}$ x $188 \mathrm{~cm}$ ebadında çift kişilik çarşaf.

\section{Sonuç ve Öneriler}

Çalıklı köyünde el sanatlarına verilen değer eskiden olduğu gibi devam etmektedir. El yapımı ürünler çeyizlerin vazgeçilmez eşyaları arasındadır. İşlemeler, el örgüsü çoraplar çeyizlerin büyük bölümünü oluşturmaktadır. Yörede kilim ve kumaş dokumacılığı bazı sebeplerden dolayı azalmaktadır. Önceden birçok evde kilim, kumaş dokumak için tezgâh bulunurken, günümüzde tezgâhlar bozulmakta, dokumayı bilen kişi sayısı azalmakta, 
dokumacılığı sürdürme gayretinde olan Türkan Zulfikarova gerekli iplik birikimi yaptıktan sonra aile ihtiyacını gidermek için tezgâhını kurarak çarşaflık dokuma yapmaktadır.

Dokunan çarşaflık kumaşların hammadde özellikleri incelendiğinde, eski dokumalarda el eğirmesi pamuk ipliğinin, günümüzde ise tütünlerin dizildiği pamuk ipliklerinin bazı işlemlerden geçirilerek tekrar kullanıldığı görülmüştür. Çarşaflık el dokuması kumaşların sık dokunmuş kumaş olmadığı, çözgülerde ve atkılarda doğal pamuk ipliği renginin tercih edildiği, atkı ipliklerinde bu ipliklere ilave olarak yatay bant desenlerini oluşturmak için farklı renklerde pamuk ipliklerinin kullanıldığı belirlenmiştir. Dokuma tezgâhında $75 \mathrm{~cm}$ eninde kumaş dokunduğu ve bir çarşaf boyuna gelindiğinde kırmızı iplikten atkı atılarak işaret konulduğu, bu bölümlere "Çav" denildiği tespit edilmiştir. Tek kişilik çarşafların 2 çav, çift kişilik çarşafların 3 çavın birleştirilmesinden meydana geldiği görülmüştür.

Dünyada sanayinin gelişmesi, birçok alanda makine üretiminin artması, el sanatı üretimini olumsuz yönde etkilemiştir. Geleneksel el dokuması kumaşüretimini azaltan nedenler arasında hazır ipliklerin, makine dokuması kumaşların ucuz ve kolay erişilebilir olması bulunmaktadır.

Geleneksel yöntemlerle ipliğin hammaddesinin elde edilmesi, eğirilmesi, boyanması, kumaşların dokunması baştan sona emek ve vakit gerektiren aşamalardır. Makine üretimi ucuz ve kolay elde edilebilir olmasına karşın el üretimindeki estetik niteliğe sahip değildir. El dokuması kumaş üretimi bir kültür mirasıdır, kaybolmaması için desteklenmesi gerekmektedir. Türkan Zulfikarova'nın elindeki kısıtlı imkânları değerlendirerek atasından öğrendiği bu sanatı gelecek kuşaklara aktarma çabası örnek bir davranıştır. Çalıklı köyünde dokuma usta sayısının gün geçtikçe azalması, geleneksel bez dokumacılığının kaybolma tehlikesini ortaya çıkartmıştır. Yapılan araştırmada, dokuma bilen kişi sayısının azalmasının yanı sıra ekonomik şartların yetersizliği, iplik tedarik edilememesi, el dokuması kumaş üretimini durma noktasına getirdiği tespit edilmiştir. İpliğin uygun fiyata alınamaması, tütün üretimi sonucu dizi pamuk ipliklerinin biriktirilerek yeterli miktarda elde edilene kadar dokumanın bekletilmesi tezgâhların kurulumunu geciktirmekte, üretim miktarını azaltmaktadır. Dokuma yapacak kişilerin projelerle desteklenmesi, dokuma kumaşlar için hammadde temini, açılan kurslarla dokuma işlem 
basamaklarının kursiyerlere öğretilmesi, elde edilen dokumalara pazar olanaklarının sağlanması, yöre insanı için geçim kaynağı oluşturacak, ata sanatının sürdürülmesine imkân sağlayacaktır.

\section{KAYNAKÇA}

Adiller, S. (2013). "Alikoç Köyü (Makedonya) Özelinde Kadının Evlilik Göçü", Istanbul Üniversitesi Sosyoloji Dergisi, İstanbul: İstanbul Üniversitesi Yayınları, Sayı 27, s.177-195.

Ercilasun, A. B. ve Akkoyunlu, Z. (2015). Kaşgarlı Mahmud Divanu Lugatit Türk, Ankara: Türk Dil Kurumu Yayınları.

Genç, R. (1997). "Kaşgarlı Mahmud'a Göre XI. Yüzyılda Türklerde Dokuma ve Yaygı İşleri”, Arış Üç Aylık Halı, Dokuma ve Işsleme Sanatları Dergisi, Ankara: Atatürk Kültür Merkezi Yayınları, Sayı 3, s.8-16.

Karabacak, K. (2017). "Türkiye'de Tütün Tarımı ve Coğrafi Dağılışı", Coğrafi Bilimler Dergisi, Ankara: Ankara Üniversitesi Yayınları, Sayı 1, s.27-48.

Macit, H. ve Tayyar, A. E. ve Macit A. Ş. ve Alan, G. (2019). "Tekstil Sektöründe Geri Dönüşüm Olanakları ve Uşak İli'nde Güncel Durum”, Uşak Üniversitesi Fen ve Doğa Bilimleri Dergisi, Uşak: Uşak Üniversitesi Yayınları, Sayı 2, s.91-102.

Nasrattınoğlu, Ü. İ. (2015). Halk Kültürü I, Makaleler, Ünlü Halkbilimciler, Ankara: Fark Dijital ve Ofset Baskı Merkezi Yayınları.

Nureski, D. (2016). “Osmanlı'dan Günümüze Makedonya'daki Türk Kültürü ve Makedonya'nın Türk Kültür Tarihindeki Yeri ve Önemi”, Avrasya Etütleri Dergisi, Sayı 50 (2), s.351-388.

Oksal, S. (1964). Küçük Türkçe Sözlük, İstanbul: Kanaat Yayınları.

Salman, F. (2004). "Türk Kumaş Sanatında Görülen Geleneksel Kumaş Çeşitlerimiz", Sanat Dergisi, Erzurum: Atatürk Üniversitesi Güzel Sanatlar Fakültesi Yayınları, Sayı 6, s. 13-42.

Sarıoğlu, H. ve Çağlayan, M. ve Yıldız H. (2011). "Kumaş Bilgisi ve Tasarımdaki Önemi”, Akdeniz Sanat Dergisi, Antalya: Akdeniz Üniversitesi Güzel Sanatlar Fakültesi Yayını, Sayı 7, s.19-24.

Soysaldı, A. (2009). Düz Dokuma Teknikleri ve Teknik Desen Çizimleri, Ankara: Atatürk Kültür Merkezi Yayınları. 
Türemen, M. ve Demir, A. ve Özdoğan, E. (2019). "Tekstil endüstrisi için geri dönüşüm ve önemi", Pamukkale Üniversitesi Mühendislik Bilimleri Dergisi, Denizli: Pamukkale Üniversitesi Yayınları, Sayı 7, s.805-809.

Uğurlu, S. (2015). "Makedonya-Valondova Hıdrellez Âdetlerinden "Yeşillenme", "Kısmet Kapama" ve "Martufal Çekme" Âdetleri", Türük Uluslararası Dil, Edebiyat ve Halkbilimi Araştırmaları Dergisi, Bolu, Sayı 5, s.37-66.

Ünver, S. (2010). 55. Kuruluş Yıldönümünde Halk Kültürü Araştırmaları Kurumu, Ankara: Lazer Ofset Yayınları.

Yılmaz, N. ve Anmaç, E. (2000). Basit Yapılı Dokuma Örgüler, İzmir: Dokuz Eylül Üniversitesi Yayınları.

\section{Internet Kaynakları}

“Mutaf", https://sozluk.gov.tr/?q=\&aranan=, Erişim tarihi: 27.04.2020.

\section{Kaynak Kişiler}

Zulfikarova, P., (2019). Pembe Zulfikarova ile Çalıklı çarşaf dokumaları konulu görüşme, Makedoya/Valandova/Çalıklı: Mayıs.

Zulfikarova, T., (2019). Türkan Zulfikarova ile Çalıklı çarşaf dokumaları konulu görüşme, Makedoya/Valandova/Çalıklı: Mayıs.

\section{Görsel Kaynaklar}

Görsel 1. Çalıklı Camisi'nde Serili Kilimin Çözgü ve Atkı İpliği Yün, Ebadı $150 \mathrm{~cm}$ x 220 cm'dir. Üç Parça Dokunan Kilim Birleştirilmiştir. Dokumada Sökülmeler Mevcuttur. Küçükkurt Arşivi, Çalıklı, 2019.

Görsel 2. Fırtışka ve Çıkrık. Türkan Zulfikarova Çıkrığının Başında Görülmektedir. Küçükkurt Arşivi, Çalıklı, 2019.

Görsel 3. Çözgü İpliklerinin Birbirine Eklenmesi ve Farklı Renk İpliklerin Birbirine Dolanmasıyla Elde Edilen Desen Hareketi. Küçükkurt Arşivi, Çalıklı, 2019.

Görsel 4. Bezayağı Dokuma Tekniğinin Çizimi. Çözgü İpliği; Beyaz, Atkı İpliği; Mavidir. Küçükkurt Arşivi, Afyonkarahisar, 2020.

Görsel 5. Eni 75 cm, Boyu 20 m Olan Tezgâhtan Çıkarılmış Çarşaflık Dokuma Kumaş. Küçükkurt Arşivi, Çalıklı, 2019. 
Görsel 6. Dokumanın 188 cm Uzunluğuna, Bir Çarşaflık Boya Geldiğini İşaretleyen Kırmızı Atkı. Küçükkurt Arşivi, Çalıklı, 2019.

Görsel 7. Türkan Zulfikarova'nın Dokuduğu, İki Çavın Birleştirildiği, $150 \mathrm{~cm}$ x $188 \mathrm{~cm}$ Ebatlarında Tek kişilik Çarşaf. Küçükkurt Arşivi, Çalıklı, 2019.

Görsel 8. Türkan Zulfikarova'nın Dokuduğu, Üç Çavın Birleştirildiği, 225 cm x 188 cm Ebatlarında Çift Kişilik Çarşaf. Küçükkurt Arşivi, Çalıklı, 2019.

Görsel 9. 75 cm x 20 m olan çarşaflık kumaş. Küçükkurt arşivi, Çalıklı, 2019.

Görsel 10. 225 cm x 188 cm ebadında çift kişilik çarşaf. Küçükkurt arşivi, Çalıklı, 2019.

Tablo 1. Çarşafıı kumaşların dokunmasında kullanılan atkı ve çözgü ipliklerinin özellikleri. Küçükkurt, 2020.

Tablo 2. Çarşaflık kumaş dokumalarının teknik özellikleri. Küçükkurt, 2020. 